\title{
Relationship between dentists' career choice motivation and job satisfaction in Gwangju
}

\author{
Jin Young Chang ${ }^{\dagger}$, Hyun Hee Choo ${ }^{\dagger}$, Jin-Hyoung Cho, and Min-Seok Kim* \\ Dental Research Institute, School of Dentistry, Chonnam National University, Gwangju 61186, Republic of Korea
}

(Received Jul 3, 2017; Revised version received [1] Oct 20, 2017 [2] Nov 17, 2017; Accepted Nov 20, 2017)

\begin{abstract}
The aims of this study were to investigate dentists' career-choice motivation and job satisfaction, and to find the relationships between dentist's career-choice motivation and job satisfaction in Gwangju. The survey was performed by visiting 100 dental hospitals and clinics in Gwangju. Data were obtained from 144 dentists; 10 were excluded because they didn't respond. The survey consists of 17 items about career choice and 29 about job satisfaction (Korean Dentist satisfaction survey. KDSS). Data were analyzed by SPSS 19.0. The three highest aspects among the 17 items about career-choice motivation were high professional status (85.7\%), providing a secure career (65.4\%), and opportunity to care for/help people (48.1\%). On the other hand, the lowest aspect was science-based occupation (4.5\%). Multiple regression analysis identified a model including perception of income, delivery of care. and professional time that accounted for $26.2 \%$ of the variation in overall job satisfaction. This study suggests that dentists who choose an opportunity to care for/help people and to have a secure career score high in overall job satisfaction. The findings of this study will be helpful to increase job satisfaction among Korean dentists.
\end{abstract}

KEY WORDS: Career-choice motivation, Dentist, Job satisfaction

\section{서 론}

대부분의 사람들은 직업을 가지고 살아간다. 직업을 선 택하는 과정과 선택한 직업을 행함으로써 얻는 만족감 혹 은 불만족감은 사람의 삶의 질을 결정하는 매우 큰 요소 이다. 사람이 직업을 선택할 때 고려하는 영향요인들은 시 대적 선호, 개인적 선호, 사회적 인식 등이며 임금수준, 도 전과 책임감, 고용 안정성, 발전 가능성, 지역적 위치, 복 지 등이다[1].

지금까지 치과의사의 직업선택동기에 대한 연구는 주로 치과대학학생들을 대상으로 한 연구가 많았다. 영국 맨체스 터 대학의 의과대학과 치과대학 학생들의 진로선택동기에 관한 연구를 시행했는데 이 연구에서 치과대학학생들은 진 로선택의 이유로 안정성과 지위, 높은 수입을 선택하였고 의 과대학학생들은 이타주의를 가장 많이 선택하였다[2]. 영국 King's college London 치과대학 5학년 학생들을 대상으로

\footnotetext{
${ }^{\dagger}$ This two authors contributed equally as the first authors.

*Corresponding author: Min-Seok Kim

Department of Oral Anatomy, School of Dentistry, Chonnam National University, 77 Yongbong-ro, Buk-gu, Gwangju 61186, Republic of Korea Tel.: +82-62-530-4823, Fax: +82-62-530-4829

E-mail: greatone@jnu.ac.kr
}

한 연구에서는 성별과 인종에 따른 치의학과 선택동기에 대한 조사를 시행하여 '전문적인 직업', '사람들의 건강을 돌봄'이 치과대학 학생들의 진로선택동기의 큰 요소임을 밝혔다[3]. 우리나라에서 의학계열의 진로선택동기에 관한 연구로는 경희대학교 의학전문대학원과 의과대학학생들의 진로선택동기와 도덕판단력에 대한 비교에 관한 연구가 있다. 두 집단 모두 타인을 돌보고 다른 사람에게 봉사하 는 것이 직업선택의 가장 큰 동기라고 하였다[4].

직업만족(job satisfaction)이란 얼마나 직업에 만족하고 있는가를 나타내는 개념적 지표이다. 직업이나 직업 경험 으로부터 발생하는 정서적인 상태를 말하며 이는 개인의 기대치와 이에 상응하는 충족 정도에 따라 만족, 불만족으 로 표출되는 매우 주관적인 판단으로 볼 수 있다. 치과의 사들의 직업만족도는 지금까지의 많은 연구에서 다양한 방법으로 측정되었다. 558명의 캘리포니아 개원 치과의사 를 상대로 54 개 문항의 직업만족도에 관한 조사를 시행한 1990 년대 이전 연구에서는 미국 내 치과의사들의 상당수 $(60 \sim 75 \%)$ 가 그들의 직업에 대해 만족하였으나 점차 불만 족 요소가 증가되고 있음을 지적하였다[5]. 미국 내 2,081 명의 개원의를 대상으로 한 조사에서는 $50 \%$ 정도만이 또 다시 치과의사를 직업으로 선택하겠다는 결과를 보고한 바 있으며[6], 또 다른 미국 내 1,258 명의 치과의사들에 대 
한 연구에서는 1990 년대 초반 이후 수입의 증가로 인하여 불만족 요인들이 감소되고 있다고 하였다[7]. 우리나라에 서는 216 명의 대구광역시 개원치과의사들을 대상으로 직 업만족도를 조사한 연구에서 교육수준, 개원기간, 휴무일 수 및 월평균 보험 청구액이 높을수록 직업만족도가 증가 한다고 하였고[8], 144 명의 개원치과의사들의 직업소진과 직업만족도의 관련에 관한 연구에서는 진료내용적인 면이 가장 만족스럽고 개인적 시간 확보측면에서 치과의사들이 가장 불만족한다고 발표하였다[9].

치과의사는 치의학에 대한 전문적 지식을 가지고 환자 의 악안면 부위를 치료하는 대표적인 전문직으로 높은 수 준의 지식수준과 의료행위에 대한 사회적 중요성, 책임감 을 필요로 하는 직업이다. 또한 주변 보조 인력과의 관계, 환자와의 관계 등 원만한 인간관계를 필요로 한다. 이렇게 치과의사라는 직업은 높은 지적능력, 임상능력 그리고 대 인관계 능력 등 복합적인 능력을 요구하는 직업이고 과거 의 연구들이 모두 치과대학생들의 직업선택동기만을 조사 하였기 때문에 학교를 졸업하고 임상경험이 있는 치과의 사들이 과거의 직업선택동기와 관련하여 만족도에 어떻게 영향을 받는지 알아보는 것은 단지 현재 치과의사들의 직 업만족도만을 조사하는 것에서 나아가 치과대학 및 치의 학전문대학원의 학생들의 교육측면에서도 시사하는 바가 있다 하겠다. 즉, 직업선택의 동기와 직업만족도의 관련성 을 살펴보고 치과의사라는 직업을 선택하게 된 동기를 치 과대학이나 전문대학원에서 적절하게 교육하고 발전시킬 수 있다면 치과의사라는 직업의 질을 더 높이는 결과를 가 져올 수 있을 것이다. 따라서 본 연구는 광주광역시 일부 지역 치과의사들의 직업선택동기와 직업만족도를 파악하 여 두 요소간의 관련성을 파악하기 위하여 시도되었다.

\section{연구대상 및 방법}

광주광역시 치과의사회에 등록된 치과병원, 의원을 방 문하여 144 명의 치과의사로부터 설문을 획득하였다. 이중 직업선택동기와 직업만족도를 측정한 문항에 무응답이 많 은 10 명의 자료를 제외시키고 134 명의 자료를 최종 분석 대상으로 선정하였다.

본 연구에는 설문지가 사용되었고, 사용한 설문지는 세 부분으로 구성되었다. 첫 번째 부분은 인구사회학적 요인 에 대한 문항이며, 두 번째 부분은 직업선택동기, 세 번째 부분은 직업만족도와 관련된 문항으로 구성되었다.

\section{설문제작 및 문항구성}

인구사회학적 요인

성별은 남녀로 나누고, 연령은 임상경력을 기준으로 중
간값인 45 세로 나누어 구분하였다. 학력에 따른 동기 및 만족도 차이가 있을 것으로 예상하여 치의학사, 치의학석 사, 치의학박사로 나누었다.

\section{직업선택동기}

다양한 분야에서 직업선택동기에 대한 설문을 하였으나 치과의사를 대상으로 한 경우는 없었다. 이에 치과의사의 직업선택동기를 조사하기 위하여 Crossley 등[2]에 의해 고안된 설문을 사용하였다. 이는 영국 맨체스터 대학의 의 과, 치과대학학생들의 진로선택동기를 조사하기 위해 작 성된 설문이며 지위와 안정성(Status and security), 직업적 특성(The nature of the occupation), 직업적 기회(Career opportunities), 환자를 진료하고 사람들과 함께 일함(Patient care and working with people), 개인적 기술의 사용(Use of personal skills), 과학적 흥미(Interest in science)에 관련된 17 개의 문항으로 구성되어 있다. 각 문항에 대하여 '그렇 다' 또는 ‘아니다’로 표시하고 직업선택 동기를 여러 개 선택할 수 있도록 다중응답을 허용하였다.

\section{직업만족도}

치과의사를 대상으로 한 직업만족도를 조사하기 위한 측정도구로 Shugars 등[5]에 의해 개발된 DSS(Dentist Satisfaction Survey)설문을 Jeong 등[10]이 우리나라의 실 정에 맞도록 KDSS (Korean Dentist Satisfaction Survey)로 변형한 KDSS 설문을 사용하였다. KDSS 설문은 전반적인 만족도(overall job satisfaction), 소득(perception of income), 개 인적인 여가시간(personal time), 진료활동과 관련된 시간 (professional time), 다른 치과인력과의 관계(staff), 환자와의 관계(patient relations)및 진료내용(delivery of care)등으로 나 누어 7 개 요인 29문항으로 구성되어 있다. 본 연구에서는 $\mathrm{KDSS}$ 를 이용하여 치과의사의 직업만족도를 측정하였다.

각 문항에 대한 만족도를 5 점 리커드 척도로 측정하였 다. '매우 그렇다'를 5점, ‘그렇다’를 4점, ‘그저 그렇다'를 3점, ‘그렇지 않다’를 2점, 그리고 ‘전혀 그렇지 않다'를 1 점으로 하였다. 29 개의 문항에 대해 각 요인별 내적일치도 를 나타낸 Cronbach's $\alpha$ 계수는 일반적인 만족도 0.80 , 소 득 0.76 , 개인적인 여가 시간 0.81 , 진료활동과 관련된 시 간 0.56 , 다른 치과인력과의 관계 0.82 , 환자와의 관계 0.71 , 진료내용 0.72 로 각 요인별 신뢰도가 높은 것으로 나 타나 설문도구의 내적일치도가 충분하다는 것을 알 수 있 었다.

\section{통계분석}

직업선택동기는 ‘그렇다' 또는 ‘아니다’로 표시된 각 문 항에 대하여 성별, 연령, 학력에 따른 응답율의 차이를 chai-square test를 통해 분석하였다. 기대빈도가 5 보다 작 
은 셀이 전체의 $20 \%$ 이상인 경우에는 Fisher's exact test를 통해 분석하였다. 직업만족도는 부정적인 문항의 경우 역 환산을 통하여 점수가 높을수록 직업만족 정도가 높은 것 으로 해석하였다. 직업만족도 각 세부요인들인 소득, 개인 적인 여가시간, 진료활동과 관련된 시간, 다른 치과인력과 의 관계, 환자와의 관계 및 진료내용이 전반적인 만족도에 미치는 영향력을 알아보기 위하여 단계별 변수선택법 (Stepwise)을 사용한 중회기분석을 시행하였다. 직업선택 동기와 직업만족도의 연관성을 보기 위하여 직업선택동기 의 응답에 따른 각 요인별 직업만족도의 차이를 t-test을 통하여 분석하였다. 통계분석은 SPSS(IBM SPSS Statistics 19, SPSS Inc, Chicago, Ill, USA)를 이용하였으며, 통계적 유의수준은 0.05 로 하였다.

\section{결 과}

\section{인구사회학적 특성}

성별, 연령, 학력에 대하여 조사하였으며 설문에 응답한 자 134명 중 남성은 92명, 여성은 42명이었고, 45세 이상 은 62명, 45 세 이하는 72 명이었다. 학력에 따라 나누어 보 면 치의학사는 48 명, 치의석사는 33 명, 치의학박사는 53 명 이었다(Table 1).

\section{직업선택동기}

높은 전문성(high professional status), 안정성(provide a secure career), 다른 사람을 돕고 진료함(opportunity to care for/help people)이 가장 높은 3 가지 직업선택동기로 나타났다. 반면에 과학에 대한 관심(general interest in science)과 정신적 기술을 필요로 함(requires use of mental skills), 과학을 기초로 하는 직업(science based occupation) 은 낮은 응답률을 보였다(Fig. 1).

성별로 나누어 보면 남성은 높은 전문성(high professional status), 독립성(self employment and independence), 다른 사람을 돕고 진료함(opportunity to care for/help people), 책임감 있는 직업(responsible job)의 항목에서 여성보다 높은 응답률을 보였으며 특히 독립성(self employment and independence) 항목에서는 유의할만한 차이를 $(\mathrm{p}=0.034)$ 나

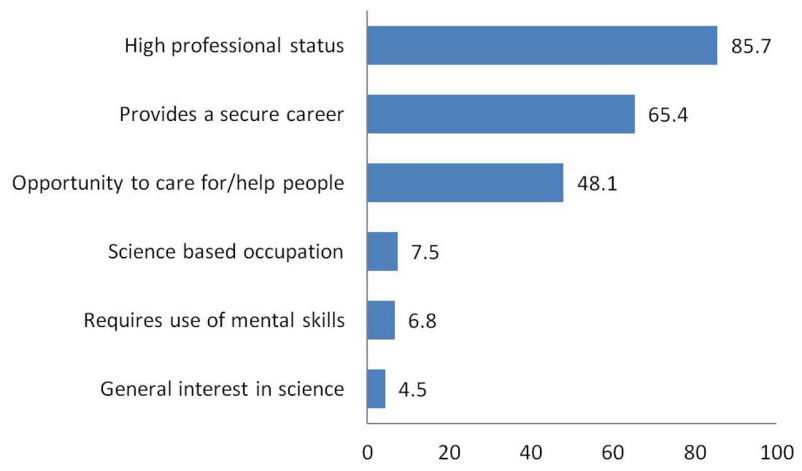

Fig. 1. Factors influencing Career choice motivation of dentists $(n=134)$.

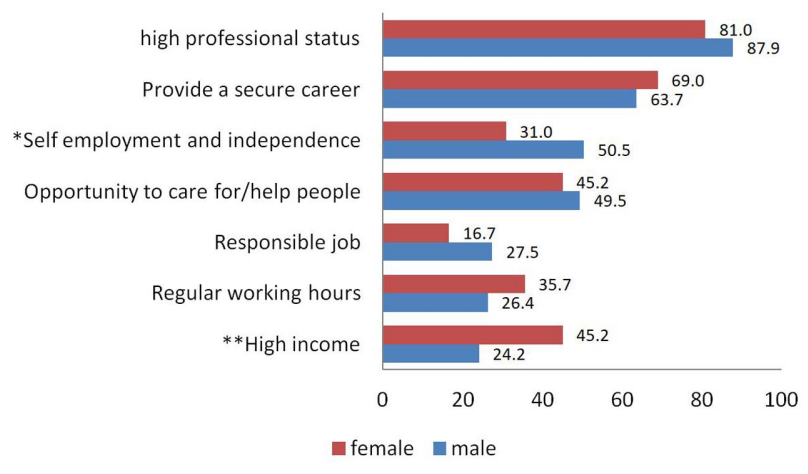

Fig. 2. Factors influencing career choice motivation of dentists by sex: multiple resposes $(n=134)$.

*Males were significantly higher than female, $\mathrm{p}=0.034$.

**Female were significantly higher than female, $p=0.013$.

타냈다. 여성은 안정성(provide a secure career), 일정한 진 료시간(regular working hours), 높은 수입(high income)에 서 여성에 비하여 높은 응답률을 보였으며 특히 높은 수 입(high income) 항목에서 유의할만한 차이를 $(\mathrm{p}=0.014)$ 나 타냈다(Fig. 2).

연령에 따라서는 45 세를 초과하는 치과의사들은 높은 전문성(high professional status), 안정성(provide a secure career), 다른 사람을 돕고 진료함(opportunity to care for/ help people) 등에서 45세 이하의 치과의사보다 높은 응답 률을 보였다. 45세 이하는 일정한 진료시간(regular working hours), 높은 수입(high income), 흥미로운 직업(interesting career)에서 높은 응답률을 보였으며 흥미로운 직업(interesting

Table 1. Sex, Age, and Educational level of Subjects $(n=134)$

\begin{tabular}{rcccrrrr}
\hline & under $45 \mathrm{y}$ & over $45 \mathrm{y}$ & Total & DDS & DDS, MS & DDS, Ph.D & Total \\
\hline \multirow{2}{*}{ Male } & 43 & 49 & 92 & 30 & 19 & 43 & 92 \\
& 49.4 & 42.6 & & 33.0 & 22.7 & 36.4 & \\
\multirow{2}{*}{ Female } & 29 & 13 & 42 & 18 & 14 & 10 & 42 \\
& 22.6 & 19.4 & & 15.0 & 10.3 & 16.6 & \\
\hline Total & 72 & 62 & 134 & 48 & 33 & 53 & 134 \\
\hline
\end{tabular}




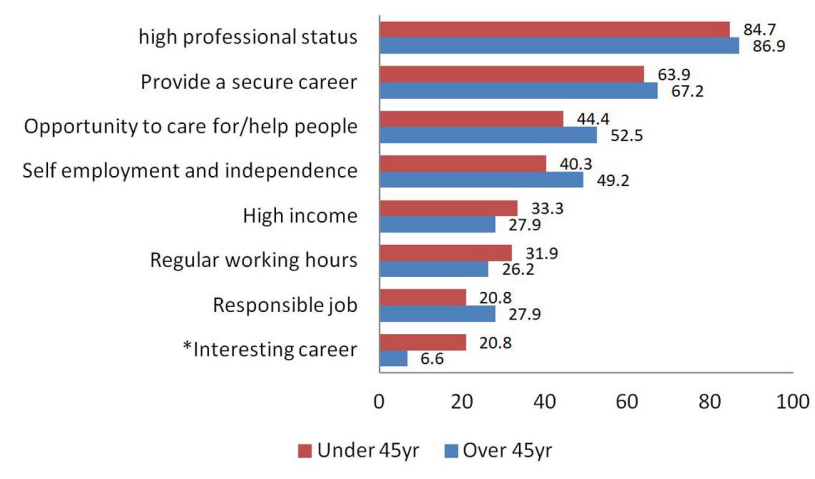

Fig. 3. Career choice motivation according to the age. *under $45 \mathrm{y}>$ over $45 \mathrm{y}, \mathrm{p}=0.019$.

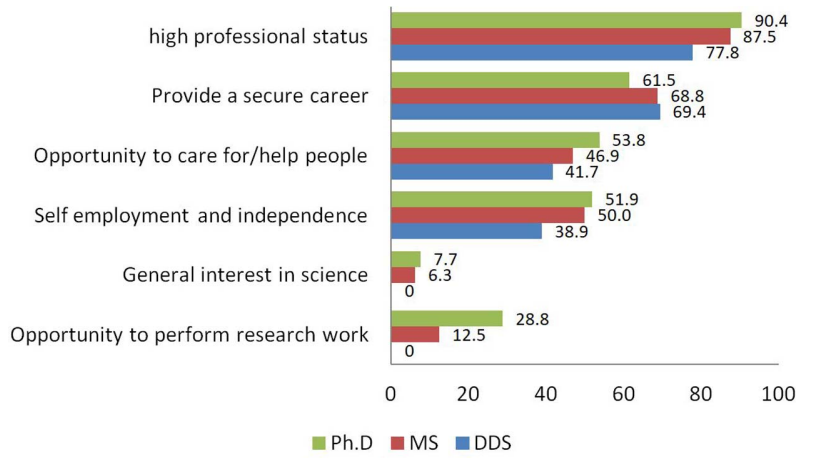

Fig. 4. Career choice motivation according to the education. ${ }^{*} \mathrm{p}=0.001$.

career)은 유의한 차이( $\mathrm{p}=0.019)$ 를 나타냈다(Fig. 3).

높은 전문성(high professional status), 다른 사람을 돕고 진료함(opportunity to care for/help people), 독립성(self employment and independence) 등에서 학력이 높을수록 높은 응답률을 보였다. 반면 안정성(provide a secure career)에서는 학력이 낮을수록 높은 응답률을 보였다. 특 히 과학, 연구와 관련된 문항인 연구를 할 수 있는 직업 (opportunity to perform research work), 과학에의 관심 (general interest in science)에서 학사졸업자는 응답을 한명 도 하지 않았으며 석사 및 박사과정졸업자는 유의한 높은 응답률을 나타냈다(Fig. 4).

Table 2. Factors influencing job satisfaction $(n=134)$

\begin{tabular}{lccccc}
\hline & $\mathrm{N}$ & $\mathrm{Min}$ & $\mathrm{Max}$ & Avg & $\mathrm{SD}$ \\
\hline Overall Satisfaction & 134 & 1.29 & 5.00 & 3.42 & 0.70 \\
Personal time & 134 & 1.00 & 5.00 & 3.04 & 0.82 \\
Professional time & 134 & 1.25 & 4.75 & 3.05 & 0.66 \\
Staff & 134 & 2.33 & 5.00 & 3.92 & 0.71 \\
Income & 134 & 1.20 & 5.00 & 3.16 & 0.66 \\
Patient relations & 134 & 2.50 & 5.00 & 3.44 & 0.41 \\
Delivery of care & 134 & 2.67 & 5.00 & 3.94 & 0.61 \\
\hline
\end{tabular}

Table 3. Regression analysis for factors influencing overall job satisfaction

\begin{tabular}{|c|c|c|c|c|}
\hline $\begin{array}{l}\text { Independant } \\
\text { variable }\end{array}$ & $\begin{array}{c}\text { Non-standard } \\
\beta\end{array}$ & $\begin{array}{l}\text { Standard } \\
\text { Error }\end{array}$ & $\begin{array}{c}\text { Standard } \\
\beta\end{array}$ & $\begin{array}{c}\mathrm{p} \\
\text { value }\end{array}$ \\
\hline Income & 0.259 & 0.085 & 0.244 & 0.003 \\
\hline Professional time & 0.259 & 0.083 & 0.245 & 0.002 \\
\hline Delivery of care & 0.273 & 0.092 & 0.236 & 0.004 \\
\hline
\end{tabular}

$R^{2}=0.262$.

\section{직업만족도}

전반적인 만족도(overall job satisfaction)는 3.43점이었 으며 진료내용(delivery of care), 다른 치과인력과의 관계 (staff), 환자와의 관계(patient relations), 소득(perception of income), 진료활동과 관련된 시간(professional time), 개인 적인 여가시간(personal time)의 순으로 만족도를 나타냈다 (Table 2).

직업만족도 각 세부요인들이 전반적인 만족도에 미치는 영향력을 알아보기 위하여 전반적인 만족도를 종속변수로 하는 중회기분석한 결과를 정리하였다. 오차를 최소화하 기 위하여 단계별 변수선택법(stepwise)을 사용하여 분석 하였다. 직업만족도의 구성요인 중 진료내용, 소득, 진료활 동과 관련된 시간이 전반적 만족도와 유의한 관련성이 있 었다. 이들 3 가지 요인에 의한 설명력은 $26 \%\left(\mathrm{R}^{2}=0.262\right)$ 였다(Table 3).

\section{직업선택동기에 따른 직업만족도 비교}

다른 사람을 돕고 진료함(opportunity to care for $/ \mathrm{help}$ people)을 선택한 응답자는 전반적인 만족도(overall job satisfaction), 소득(perception of income), 진료내용(delivery of care) 측면에서 유의하게 높은 만족도를 나타냈다. 높은 사회적 지위(prestigious social standing)을 선택한 응답자 는 소득(perception of income) 측면의 만족도가 유의하게 높았다. 안정성(provides a secure career)을 선택한 응답자 는 전반적인 만족도(overall job satisfaction)는 유의하게 높 지만 다른 치과인력과의 관계(staff) 측면의 만족도는 유의 하게 낮은 것으로 나타났다. 높은 수입(High income)을 선 택한 응답자는 소득(perception of income) 측면에서 유의 하게 높은 만족도를 나타내었으며 독립성(self employment and independence)을 선택한 응답자는 다른 치과인력과의 관계(staff) 측면의 만족도에서 유의하게 낮은 만족도를 나 타냈다(Table 4).

\section{ㄱ 찰}

본 연구는 광주 지역 일부 치과의사들의 직업선택동기 
Table 4. Relationship between Dentists'career choice motivation and job satisfaction

\begin{tabular}{|c|c|c|c|c|c|}
\hline \multicolumn{2}{|c|}{$\begin{array}{l}\text { Opportunity to care } \\
\text { for/help people }\end{array}$} & \multirow{2}{*}{$\begin{array}{l}\mathrm{N} \\
69\end{array}$} & \multirow{2}{*}{$\begin{array}{c}\text { Average } \\
3.29\end{array}$} & $\begin{array}{l}\text { Standard } \\
\text { Deviation }\end{array}$ & \multirow{2}{*}{$\begin{array}{c}\mathrm{p} \text { value } \\
0.039\end{array}$} \\
\hline & NO & & & 0.75 & \\
\hline OS & YES & 64 & 3.53 & 0.59 & \\
\hline \multirow{2}{*}{ IN } & NO & 69 & 3.05 & 0.66 & 0.048 \\
\hline & YES & 64 & 3.28 & 0.65 & \\
\hline \multirow{2}{*}{$\mathrm{DC}$} & NO & 69 & 3.80 & 0.58 & 0.006 \\
\hline & YES & 64 & 4.08 & 0.61 & \\
\hline \multicolumn{6}{|c|}{ Prestigious social standing } \\
\hline \multirow{2}{*}{ IN } & NO & 100 & 3.06 & 0.64 & 0.002 \\
\hline & YES & 33 & 3.47 & 0.63 & \\
\hline \multicolumn{6}{|c|}{ Provides a secure career } \\
\hline \multirow{2}{*}{ OS } & NO & 46 & 3.22 & 0.66 & 0.023 \\
\hline & YES & 87 & 3.50 & 0.69 & \\
\hline \multirow{2}{*}{ ST } & NO & 46 & 4.10 & 0.67 & 0.024 \\
\hline & YES & 87 & 3.81 & 0.71 & \\
\hline \multicolumn{6}{|c|}{ High income } \\
\hline \multirow{2}{*}{$\mathrm{IN}$} & NO & 92 & 3.08 & 0.59 & 0.026 \\
\hline & YES & 41 & 3.35 & 0.78 & \\
\hline \multicolumn{6}{|c|}{ Self employment and independence } \\
\hline \multirow{2}{*}{ ST } & NO & 74 & 4.06 & 0.67 & 0.005 \\
\hline & YES & 59 & 3.72 & 0.71 & \\
\hline
\end{tabular}

와 직업만족도를 알아보고 그 관련성을 평가함으로써 치 과의사들의 직업만족도 향상을 위한 자료를 제공하고자 하였다.

치과의사를 직업으로 선택한 이유로는 높은 전문성, 안 정성, 다른 사람을 돕고 진료함이 가장 높은 동기로 나타 났다. 이는 영국 맨체스터 대학의 치과대학생들의 직업선 택동기와 동일했다[2]. 영국과 우리나라의 상이한 의료체 계에도 불구하고 전문성과 안정성과 같은 점이 직업을 선 택함에 있어 큰 영향을 준다는 점을 알 수 있고, 기존의 연구에서 주로 대학생과 전문대학원생들을 상대로 조사했 을 때 밝혀졌던 직업선택동기(진로선택동기)와 임상경력 이 있는 현직 치과의사들의 직업선택동기가 유사함을 알 수 있다. 특히 치과의사가 가지는 높은 전문성으로 인해 직업을 선택한 경우가 압도적으로 많았다.

남녀에 따른 직업선택동기에서 남성은 전문성과 독립성 을 선택한 반면 여성은 안정성과 높은 수입을 선택하였다. 이 같은 결과는 Gallagher 등[3]이 영국 치과대학 5학년 학 생들을 대상으로 하여 얻은 남성은 전문성, 독립성 항목에 서, 여성은 안정성 항목에서 높게 나타난 결과와 유사하다. 반면 과학에 대한 흥미에 관한 항목은 우리나라에선 매우 낮은 응답률을 보였으나 Gallagher 등[3]에 의한 연구에서 는 높은 응답률을 나타냈다. 이는 우리나라 기초 및 임상
에서의 연구활동이 상대적으로 소수의 치과의사들에 의해 서만 행해지고 있다는 것을 의미하는 결과라 하겠다.

다음으로 연령에 따른 직업선택동기에서 45 세 이하는 흥미로운 직업이라는 항목에서 높은 응답률을 보였다. 이 는 45 세 이하의 치과의사들이 상대적으로 고령의 치과의 사들 보다 직업을 선택함에 있어 다른 주변 환경 요소들 보다 자신의 흥미위주의 직업선택을 했다는 것을 나타낸 다. 이는 오늘날 직업이 단지 생계유지의 수단이 아니라 자아를 실현하고 삶의 질을 향상시키는 삶의 일부분임을 강조하고 인식하는 사회 분위기의 변화에 따른 것으로 생 각된다.

학력과 관련된 측면에서 직업선택동기를 분석했을 때 치의학사나 치의학석사, 치의학박사 모두 높은 전문성을 중시하였으나 학력이 높을수록 높은 전문성을 중시하는 경향이 컸고, 학력이 낮을수록 직업의 안정성을 중시하는 경향이 증가하였다. 이는 치의학과 학생과 전문대학원 학 생의 직업의식과 관련된 기존의 연구와도 일치한다. 또한 치과의사가 평생 연구를 할 수 있는 직업이라는 점을 직 업선택동기로 택한 학사졸업자는 한명도 없었던 반면, 석 사 및 박사과정 졸업자는 연구와 관련한 항목에 높은 응 답률을 나타낸바, 이는 $\mathrm{Kim}$ 등[4]이 의학과 학생인 경우 직업의 안정성을 두 번째로 중요한 동기로 선택하였으나 전문대학원학생의 경우 과학적 흥미를 두 번째 중요한 동 기로 선택한 것과 비슷한 결과였다.

마지막으로 직업선택동기와 직업만족도와의 관계에서 다른 사람을 돕고 진료함, 안정성을 동기로 선택한 응답자 가 전반적인 만족도가 유의하게 높은 경향을 나타냈다. 높 은 수입을 선택한 응답자는 소득 측면의 만족도가 유의하 게 높았다. 이는 치과의사라는 직업이 안정적이며 사람을 돕고 진료함으로써 만족을 하며 소득 또한 만족할 정도로 높다고 해석할 수 있다.

본 연구의 한계점으로는 첫째, 응답자수가 다른 연구들 에 비하여 적다는 것 이다. 이로 인하여 많은 응답자수를 얻은 연구 보다 정규분포에 덜 근접하여 통계학적 유의성 을 얻기 힘들었다. 둘째, 표본 수집시 직접 방문법을 사용 하였기 때문에 광주광역시 전체지역 치과의사를 대상으로 한 것이 아니고 광주광역시 일부 지역의 치과 병, 의원 밀 집지역에서 얻어진 자료들이라 일반성이 떨어진다. 셋째, 직업선택동기 설문 항목이 영국의 학생용으로 만들어진 것이라 우리나라 치과의사를 대상으로 하기에는 좀 더 고 려해야할 사항들이 있다. 이런 한계점들에도 불구하고 본 연구를 통해 치과의사들의 직업선택동기와 직업만족도사 이의 관련성을 규명할 수 있었으며, 향후 본 연구결과를 기반으로 보다 광범위한 연구가 지속된다면 우리나라 치 과의사들의 직업만족도를 향상시킬 수 있을 것으로 기대 할 수 있을 것이다. 


\section{감사의 글}

This study was financially supported by Chonnam National University (Grant number: 2014-2315).

\section{Conflict of Interest}

The authors declare that they have no competing interests.

\section{ORCID}

$\begin{array}{ll}\text { Jin Young Chang } & 0000-0003-2617-065 X \\ \text { Hyun Hee Choo } & 0000-0002-1751-9787 \\ \text { Jin-Hyoung Cho } & 0000-0002-0342-6379 \\ \text { Min-Seok Kim } & 0000-0001-5910-8268\end{array}$

\section{References}

1. Kyu LJ. Strategic and Ethical Personnel Management. Seoul: Pakyoungsa publishing; 2002.

2. Crossley ML, Mubarik A. A comparative investigation of dental and medical student's motivation towards career choice. Br Dent J 2002;193:471-473.

3. Gallagher JE, Patel R, Donaldson N, Wilson NH. The emerging dental workforce: why dentistry? A quantitative study of final year dental students' views on their professional career. BMC Oral Health 2007;7:7.

4. Kim MK, Kang JO. Comparison of career choice motivation and moral reasoning ability between students in baccalaureate and graduate-entry programs. Korean $\mathbf{J}$ Med Educ 2007;19:91-99.

5. Shugars DA, DiMatteo MR, Hays RD, Cretin S, Johnson JD. Professional satisfaction among California general dentists. J Dent Educ 1990;54:661-669.

6. Gerbert B, Bernzweig J, Bleecker T, Bader J, Miyasaki C. How dentists see themselves, their profession, the public. J Am Dent Assoc 1992;123:72-78.

7. Anderson PE. Dentists more optimistic in 1995 practice survey. Dent Econ 1995;85:34-38.

8. Jung JJ, Bae SG. Job stress and satisfaction of dentists in Taegu, Korea. J Korean Acad Oral Health 1997;21:633649.

9. Bae JD. Association between burnout and job satisfaction among Korean dentists. Graduate School of Kyungpook National University 2010.

10. Jeong SH, Chung JK, Choi YH, Sohn W, Song KB. Factors related to job satisfaction among South Korean dentists. Community Dent Oral Epidemiol 2006;34:460466. 